\title{
Atividade antimicrobiana do extrato de Anacardium occidentale Linn. em amostras multiresistentes de Staphylococcus aureus
}

\author{
Jackeline G. da Silva' ${ }^{*}$, Ivone A. Souza ${ }^{1}$, Jane S. Higino ${ }^{2}$, José P. Siqueira-Junior ${ }^{1}$, Jozinete \\ V. Pereira ${ }^{3}$, Maria do Socorro V. Pereira ${ }^{2}$ \\ ${ }^{I}$ Departamento de Biologia Molecular, Universidade Federal da Paraíba, Centro de Ciências Exatas e da \\ Natureza, 58059-900, João Pessoa, PB, Brasil, \\ ${ }^{2}$ Departamento de Farmácia, Centro de Ciências da Saúde, Universidade Federal de Pernambuco, 50740-521, \\ Recife, PE, Brasil, \\ ${ }^{3}$ Departamento de Odontologia, Centro de Ciências Biológicas e da Saúde, Universidade Estadual da Paraíba, \\ 58100-100, Campina Grande, PB, Brasil
}

\begin{abstract}
RESUMO: Plantas medicinais com propriedades terapêuticas são de grande relevância em todo o mundo, principalmente em países em desenvolvimento. A planta Anacardium occidentale Linn. é largamente usada na medicina tradicional na nossa região, como antidiarréico, para amigdalite, bronquites, artrites, e antiiflamatório. No presente estudo avaliou-se a ação antimicrobiana do extrato hidroalcóolico da casca do caule do cajueiro frente a amostras de Staphylococcus aureus resistentes e sensíveis à meticilina, obtidas a partir de pacientes internados do Hospital Universitário/Universidade Federal da Paraíba. A atividade antimicrobiana foi determinada pelo método de difusão em meio sólido para a determinação da Concentração Inibitória Mínima do extrato, e foi observada no total de 30 amostras, pela presença ou não do halo de inibição. Todas as amostras ensaiadas mostraram-se sensíveis à ação do extrato do cajueiro, com diâmetros dos halos de inibição variando de 10 a $20 \mathrm{~mm}$, demonstrando grande eficácia do cajueiro. Assim, o uso desta planta na nossa região pode inferir uma alternativa terapêutica eficiente e de baixo custo, contra infecções bacterianas causadas por Staphylococcus aureus.
\end{abstract}

Unitermos: Anacardiaceae, Anacardium occidentale, Staphylococcus aureus, atividade antimicrobiana.

\begin{abstract}
Antimicrobial activity of the hydroalcoholic extract of Anacardium occidentale Linn. against multi-drug resistant strains of Staphylococcus aureus". Medicinal plants with therapeutical properties are of great significance in the whole world, especially in developing countries. Anacardium occidentale Linn. is a plant widely used in the traditional medicine in our region against diarrhea, tonsillitis, bronchitis, arthritis, and inflammation. In this paper, the antimicrobial activity of the hydroalcoholic extract of the cashew tree stem was evaluated against samples of meticillin-resistant and meticillin-sensible Staphylococcus aureus, attained from patients interned at Hospital Universitário/Universidade Federal da Paraíba. The antimicrobial activity was determined by the diffusion method in solid milieu to determine the Minimum Inhibitory Concentration (MIC) of the extract, and it was observed in 30 samples the presence or not of inhibition zone. All the assayed samples proved to be sensible to the activity of the extract of the cashew tree, with inhibition zones diameter of 10 to $20 \mathrm{~mm}$, displaying consequently great effectiveness of the extract of the cashew tree stem. Thus, the use of this plant in our region can infer a low cost and efficient therapeutical alternative against bacterial infections caused by Staphylococcus aureus.
\end{abstract}

Keywords: Anacardiaceae, Anacardium occidentale, Staphylococcus aureus, antimicrobial activity.

\section{INTRODUÇÃO}

O desenvolvimento na quimioterapia antimicrobiana teve início na década de $30 \mathrm{com}$ a descoberta das sulfonamidas e as penicilinas (Jawetz et al., 1998). Porém nas subseqüentes décadas de 50 e 70, epidemias por Staphylococcus aureus resistentes à penicilina e linhagens multiresistentes (MRSA), chamaram a atenção para o problema da resistência adquirida aos antimicrobianos (Couto; Pedrosa, 1999). Atualmente, $S$. aureus meticilina resistente, é o maior patógeno nosocomial em infecções hospitalares e é responsável por inativar a ação de vários antibióticos, tornando a multiresistência, um grande problema de saúde pública (Stratton, 2000).

Em razão ao grande aumento da resistência de microrganismos patogênicos a múltiplas drogas, devido ao uso indiscriminado de antimicrobianos, surge 
a preocupação para a procura de novas alternativas terapêuticas (Novais et al., 2003; Antunes et al., 2006; Oliveira et al., 2006; Oliveira et al., 2007). As plantas medicinais estão dentre os produtos naturais, de grande interesse científico devido à possibilidade de empregálas como fitofármacos, por proporcionarem grandes chances de obterem-se moléculas protótipos devido a sua diversidade de seus constituintes (Nascimento et al., 2000; Pessini et al., 2003; Duarte et al., 2004; Michelin et al., 2005; Lima et al., 2006).

A planta Anacardium occidentale Linn. pertencente à família Anacardiaceae, é conhecida popularmente como cajueiro. É originária do Brasil, e utilizada na medicina tradicional, principalmente no Nordeste brasileiro com efeitos terapêuticos como: aliviar dor de dente, antiinflamatório para gengiva e garganta, bronquites, artrites, cólicas intestinais, icterícia, contra diabetes, asma e até mesmo usado como afrodisíaco (Mota, 2004; Olumayokun et al., 2004; Morais et al., 2005; Agra et al., 2007). Na literatura encontram-se atividades farmacológicas comprovadas, como sendo o cajueiro uma planta antiiflamatória (Olajide et al., 2004; Falcão et al., 2005), antidiabética (Oliveira; Salto, 1987/1989; Kamtchouing et al., 1998; Barbosa-Filho et al., 2005); inibidor da enzima acetilcolinesterase (Barbosa-Filho et al., 2006) e substâncias isoladas do fruto demonstraram ser inibidora de tirosinase (Kubo et al., 1994).

Devido ao uso intenso do cajueiro na nossa região, para fins terapêuticos, o presente trabalho teve por objetivo avaliar a ação antimicrobiana do extrato hidroalcóolico da casca do caule de Anacardium occidentale, como um tratamento alternativo para infecções causadas por Staphylococcus aureus multiresistentes.

\section{MATERIAL E MÉTODOS}

\section{Coleta da planta e obtenção do extrato hidroalcoólico}

A planta foi coletada no NUPA (Núcleo de pesquisa e Processamento de alimentos/UFPB) e indentificado por J.R. Lima do herbário Prof. Lauro Pires Xavier, com exsicata de número 31500 JPB.

$\mathrm{O}$ extrato foi obtido a partir da casca do caule da planta. A casca do caule foi colocada na estufa a $33{ }^{\circ} \mathrm{C}$ por uma semana, triturado a pó em moinho elétrico e então submetido ao processo da extração. $\mathrm{O}$ método de extração empregado foi à lixiviação ou percolação em fluxo contínuo à temperatura ambiente. $\mathrm{Na}$ lixiviação em fluxo contínuo, utilizou-se um processo onde existe a renovação constante da solução extratora (solução hidroalcoólica a 70\% v/v). Posteriormente o extrato foi concentrado em rota-vapor (Modelo Ika-Werk), a uma temperatura constante de $45{ }^{\circ} \mathrm{C}$. A concentração obtida ao nível de extrato fluído foi de 1:1 (p/v).

\section{Amostras bacterianas}

Foi utilizado no presente trabalho um total de trinta amostras de $S$. aureus de origem humana obtidas a partir de pacientes internados no Hospital Universitário Lauro Wanderley/UFPB, caracterizadas fenotipicamente como sensíveis e resistentes a meticilina (Freitas, 1992). A linhagem ATCC foi utilizada como controle de referência em todos os experimentos realizados (NCCLS, 1988).

\section{Determinação da atividade antimicrobiana - concentração inibitória mínima (CIM) do extrato da planta Anacardium occidentale Linn.}

A atividade antimicrobiana em placas foi determinada pelo método de difusão em meio sólido para a determinação da Concentração Inibitória Mínima (CIM) do extrato hidroalcoólico de Annacardium ocidentale, sobre as linhagens bacterianas. As linhagens de $S$. aureus hospitalares foram cultivadas em caldo nutritivo (BHI - Brain Heart Infusion - DIFCO) incubadas a $37^{\circ} \mathrm{C}$ por $18-20$ horas. Dilui-se $0,1 \mu \mathrm{L}$ do inóculo em $10 \mathrm{~mL}$ de salina $\left(10^{-1}\right)$. Foi retirado $1 \mathrm{~mL}$ e transferido para as placas sendo adicionado a $22 \mathrm{~mL}$ do meio de cultura. Após solidificação foram postas para secarem, entreabertas, na estufa a $37{ }^{\circ} \mathrm{C}$ por aproximadamente 30 minutos. Foram realizadas, depois de retirada às placas, perfurações no meio de cultura (Agar Müeller Hinton DIFCO) de aproximadamente $6 \mathrm{~mm}$ de diâmetro com ponteiras estéreis. Nos orifícios foi vertido um volume de $50 \mu \mathrm{L}$ da solução do extrato diluída, variando da diluição 1:1 até 1:1024, estas correspondendo a concentração do extrato que variaram de $100 \mathrm{mg} / \mathrm{mL}$ a $0,19 \mathrm{mg} / \mathrm{mL}$. As placas foram incubadas em estufa bacteriológica a 37 ${ }^{\circ} \mathrm{C}$ por um período de 24 horas. Foi considerada como CIM, a menor concentração do extrato que inibiu o crescimento bacteriano observada pela presença do halo de inibição. Como controle da atividade do extrato foi empregado a linhagem padrão ATCC 29213 (NCCLS, 1988). O antibiótico norfloxacina foi utilizado como controle positivo para os ensaios. O álcool etanol, a 70\% como controle negativo.

\section{RESULTADOS}

De acordo com ensaios realizados, todas as amostras ensaiadas foram sensíveis ao extrato de $A$. occidentale. Os resultados, em termos de valor da CIM para o extrato estão apresentados na Tabela 1. A Figura 1 mostra, graficamente, a determinação da CIM. A Figura 2, expressa a ação antimicrobiana in vitro do extrato hidroalcoólico de $A$. occidentale frente a uma amostra de $S$. aureus multiressistente. 


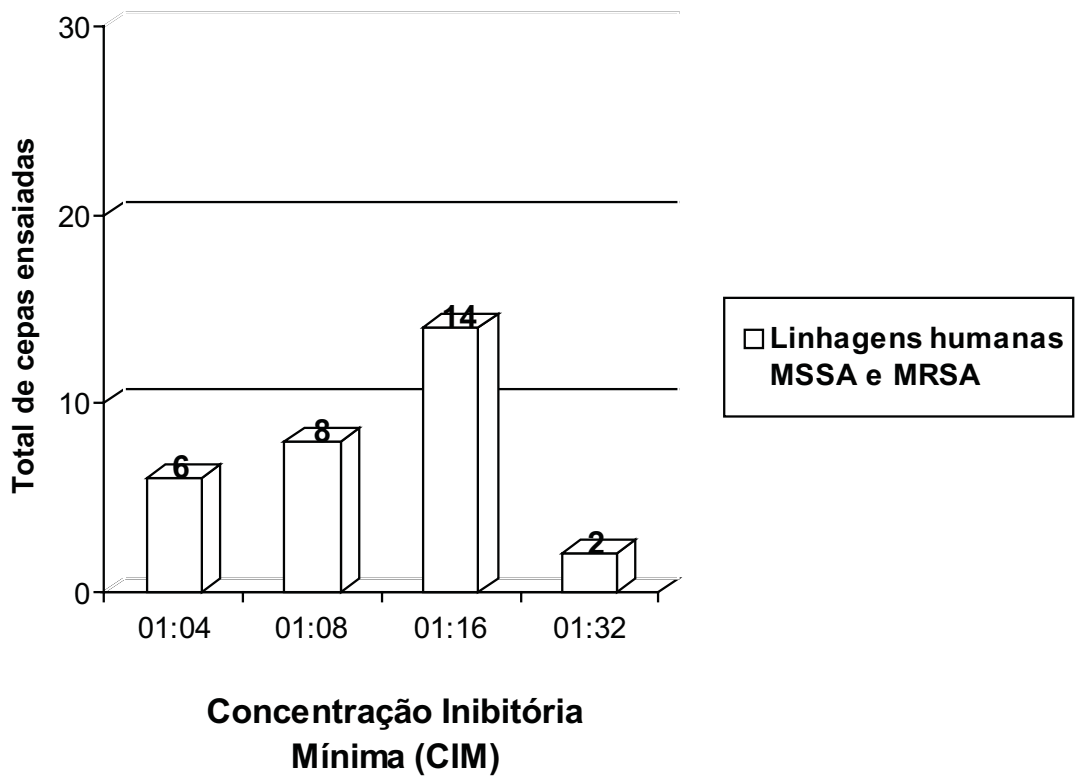

Figura 1. CIM de 30 amostras de $S$. aureus de origem humana frente ao extrato do cajueiro.

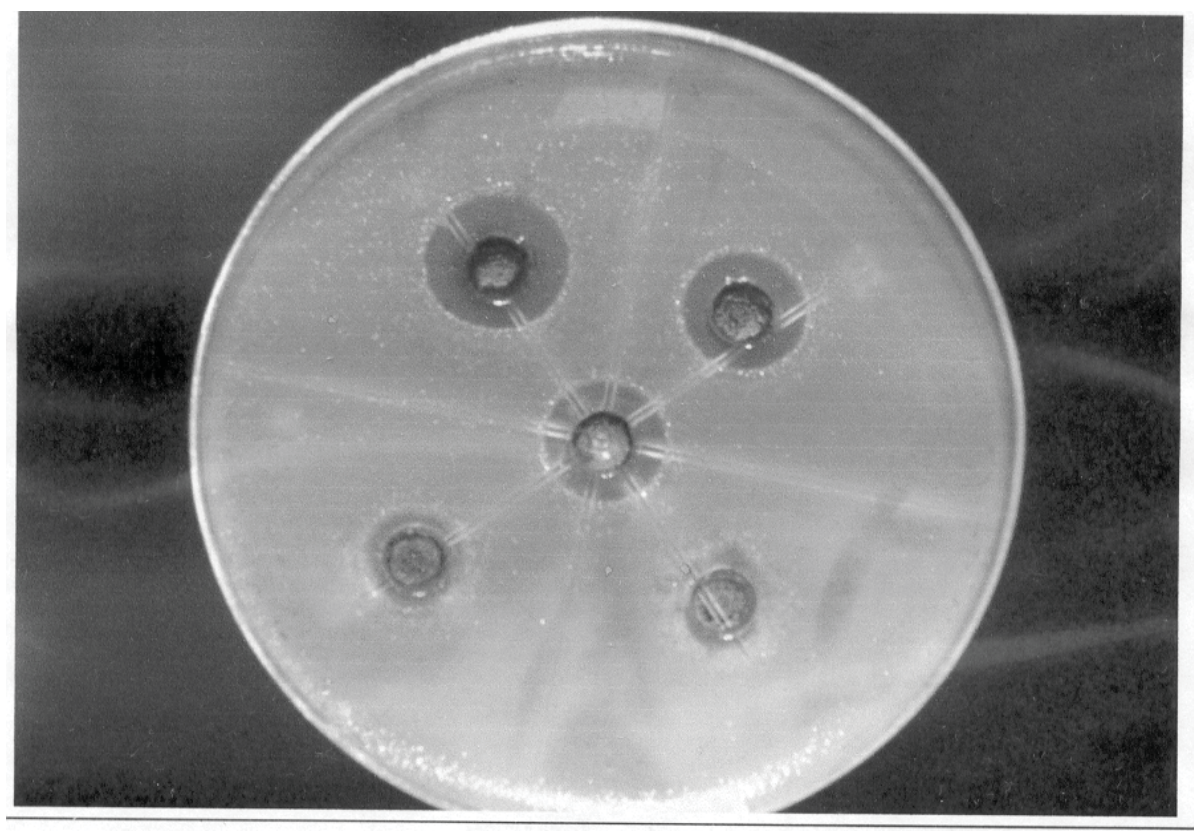

Figura 2. Atividade antimicrobiana do extrato hidroalcoólico de $A$. occidentale Linn. sobre a linhagem de S. aureus 171cc (MRSA) de origem hospitalar. 
Tabela 1. CIM do extrato hidroalcoólico de Anacardium occidentale Linn. (Cajueiro) sobre linhagens de $S$. aureus humana hospitalares.

\begin{tabular}{|c|c|c|c|c|c|c|c|c|c|c|c|}
\hline \multirow[t]{2}{*}{ Linhagens bacterianas } & \multicolumn{11}{|c|}{$\begin{array}{l}\text { Diâmetro dos halos de inibição }(\mathrm{mm}) \\
\text { Concentração do extrato (mg/mL) }\end{array}$} \\
\hline & $\begin{array}{l}\text { Extrato } \\
\text { Puro }\end{array}$ & $1: 2$ & $1: 4$ & $1: 8$ & $1: 16$ & $1: 32$ & $1: 64$ & $1: 128$ & $1: 256$ & $1: 512$ & Nor \\
\hline $01 \mathrm{H}$ & 13 & 10 & 10 & 0 & 0 & 0 & 0 & 0 & 0 & 0 & - \\
\hline $02 \mathrm{H}^{*}$ & 14 & 13 & 11 & 10 & 0 & 0 & 0 & 0 & 0 & 0 & 23 \\
\hline $03 \mathrm{H}$ & 18 & 14 & 11 & 10 & 0 & 0 & 0 & 0 & 0 & 0 & - \\
\hline $05 \mathrm{cc}$ & 16 & 14 & 11 & 10 & 0 & 0 & 0 & 0 & 0 & 0 & 34 \\
\hline $05 \mathrm{H}^{*}$ & 13 & 10 & 10 & 0 & 0 & 0 & 0 & 0 & 0 & 0 & - \\
\hline $06 \mathrm{cc} *$ & 15 & 10 & 10 & 10 & 0 & 0 & 0 & 0 & 0 & 0 & 25 \\
\hline $06 \mathrm{H}$ & 14 & 13 & 10 & 10 & 0 & 0 & 0 & 0 & 0 & 0 & 20 \\
\hline $07 \mathrm{cc}$ & 14 & 13 & 10 & 10 & 0 & 0 & 0 & 0 & 0 & 0 & - \\
\hline $08 \mathrm{cc}$ & 14 & 13 & 11 & 0 & 0 & 0 & 0 & 0 & 0 & 0 & - \\
\hline $08 \mathrm{Sn}$ & 14 & 13 & 11 & 0 & 0 & 0 & 0 & 0 & 0 & 0 & - \\
\hline $09 \mathrm{cc} *$ & 13 & 10 & 10 & 0 & 0 & 0 & 0 & 0 & 0 & 0 & 23 \\
\hline $09 \mathrm{H}$ & 13 & 12 & 10 & 0 & 0 & 0 & 0 & 0 & 0 & 0 & 36 \\
\hline $10 \mathrm{cc} *$ & 15 & 14 & 12 & 11 & 10 & 0 & 0 & 0 & 0 & 0 & 24 \\
\hline $11 \mathrm{Sn}$ & 16 & 14 & 12 & 10 & 0 & 0 & 0 & 0 & 0 & 0 & 25 \\
\hline $13 \mathrm{Sn}$ & 14 & 13 & 11 & 10 & 10 & 0 & 0 & 0 & 0 & 0 & 25 \\
\hline 19Lab* & 17 & 15 & 13 & 10 & 10 & 0 & 0 & 0 & 0 & 0 & 11 \\
\hline $102 \mathrm{cc}$ & 18 & 15 & 14 & 13 & 10 & 10 & 0 & 0 & 0 & 0 & - \\
\hline $104 \mathrm{H}$ & 15 & 14 & 13 & 10 & 0 & 0 & 0 & 0 & 0 & 0 & 31 \\
\hline $117 \mathrm{H}$ & 14 & 12 & 12 & 11 & 10 & 10 & 0 & 0 & 0 & 0 & 22 \\
\hline $119 \mathrm{H}$ & 14 & 13 & 13 & 10 & 10 & 0 & 0 & 0 & 0 & 0 & 27 \\
\hline $125 \mathrm{H}$ & 15 & 12 & 11 & 10 & 10 & 0 & 0 & 0 & 0 & 0 & 25 \\
\hline $137 \mathrm{H}$ & 14 & 13 & 13 & 12 & 10 & 0 & 0 & 0 & 0 & 0 & - \\
\hline $148 \mathrm{H}$ & 16 & 16 & 13 & 12 & 10 & 0 & 0 & 0 & 0 & 0 & 36 \\
\hline 149Lab* & 16 & 14 & 13 & 10 & 10 & 0 & 0 & 0 & 0 & 0 & 26 \\
\hline $154 \mathrm{H}$ & 14 & 13 & 10 & 10 & 10 & 0 & 0 & 0 & 0 & 0 & 23 \\
\hline $171 \mathrm{cc} *$ & 17 & 16 & 14 & 14 & 12 & 0 & 0 & 0 & 0 & 0 & 24 \\
\hline $186 \mathrm{~A}$ & 20 & 19 & 16 & 15 & 12 & 0 & 0 & 0 & 0 & 0 & - \\
\hline $259 \mathrm{I}$ & 15 & 15 & 14 & 12 & 10 & 0 & 0 & 0 & 0 & 0 & 25 \\
\hline $296 I^{*}$ & 17 & 16 & 14 & 13 & 13 & 0 & 0 & 0 & 0 & 0 & 25 \\
\hline ATCC 29213 & 17 & 16 & 14 & 13 & 12 & 0 & 0 & 0 & 0 & 0 & - \\
\hline
\end{tabular}

H, I, cc, A, Sn - Sítio - Ferida cirúrgica; *Linhagens MRSA; Nor - Norfloxacina. 


\section{DISCUSSÃO}

A resistência bacteriana aos antimicrobianos é considerada como um problema inerente à terapia antimicrobiana, por este motivo é preciso sempre a busca de novas fontes terapêuticas os quais sejam mais eficientes para o tratamento de infecções, como as bacterianas.

Os produtos naturais são uma alternativa extremamente viável, uma vez que sempre foram importantes para o descobrimento de novas drogas, sendo fornecedoras de princípio ativo e por ser também uma alternativa mais econômica no controle de doenças para países em desenvolvimento, onde a maioria das drogas é importada (Xu; Lee, 2001). Segundo Cowan (1999), atualmente um quarto da metade de todos os fármacos comercializados são originários de plantas, porém nenhum destes é usado como antimicrobiano, a grande maioria é usada como suplementos vitamícos e dietéticos.

$\mathrm{O}$ uso do cajueiro pode ser incentivado uma vez que no presente estudo, todas as linhagens demonstraram sensibilidade ao extrato da casca do cajueiro (Tabela 1). Observaram-se halos de inibição de 10 a $20 \mathrm{~mm}$, sendo considerado ativo o extrato na diluição que mostrou halos de inibição igual ou superior a $10 \mathrm{~mm}$. A inibição do crescimento apresentou-se homogênia, de acordo com o grau de concentração do extrato hidroalcoólico da planta em estudo. Houve uma diminuição proporcional do diâmetro dos halos à medida que a concentração do extrato foi diminuída conforme apresentado na Tabela 1 e Figura 2.

De acordo com a literatura, o extrato do cajueiro também possui efeito frente a bactérias gram-negativas; Proteus morgani, Psudomonas aeruginosa, Escherichia coli e Salmonella typhi, no qual o extrato demonstrou atividade antibacteriana em altas concentrações (Laurens et al., 1992). Em outros trabalhos o cajueiro também foi efetivo sobre especies de Streptococcus (Melo et al., 2006). Atividade antimicrobiana de diversos extratos vegetais de uso regional, incluindo o cajueiro, foi avaliada sobre $S$. aureus, os resultados mostraram que para $80 \%$ das linhagens, o extrato foi potencialmente ativo demonstrando halos de inibição superior a $15 \mathrm{~mm}$ (Cebalhos et al., 1993).

Os resultados aqui apresentados também corroboram com outra avaliação prévia da ação antimicrobiana do extrato metanólico da casca do cajueiro, frente a diversas bactérias entre elas uma linhagem de $S$. aureus realizadas por Akinpelu (2001). Neste estudo prévio a zona de inibição do crescimento da bactéria foi de $17 \mathrm{~mm}$, assemelhando-se aos nossos resultados. Em relação à determinação da CIM, nos nossos ensaios foi observado, variadas concentrações. Dentre as concentrações avaliadas, a maioria das amostras $14(46,6 \%)$ apresentou a CIM de 1:16, correspondendo a $6,25 \mathrm{mg} / \mathrm{mL}$ do extrato, salientando que dentre estas 14 cepas, 4 amostras são multiresistentes (MRSA); enquanto que a minoria das amostras $2(6,6 \%)$ apresentaram menor CIM de 1:32, a qual corresponde a 3,1 $\mathrm{mg} / \mathrm{mL}$ do extrato, porém estas amostras não são multiresistentes (MSSA) (Figura 1). A não semelhança na CIM com resultados de Akinpelu (2001), pode ser devido aos diferentes padrões de resistência das amostras ensaiadas no presente trabalho, previamente determinada por Freitas, (1992).Somando-se a esta razão à extração com diferentes solventes utilizados e a época de coleta podem influenciar na atividade farmacológica da plantas, pois segundo Cechinel Filho e Yunes (1998) a biossíntese de compostos secundários depende de fatores ambientais como clima e tipo de solo.

Considerando a riqueza de constituintes presentes em plantas, a atividade antimicrobiana positiva do extrato do cajueiro frente a amostras de $S$. aureus, pode ser devido à presença de compostos como taninos (compostos polifenólicos) e alcalóides previamente encontrados na planta, uma vez que estes compostos têm comprovada ação antimicrobiana, e que compostos fenólicos possuem uma ação inespecífica sobre o microrganismo, rompendo a parede celular bacteriana, inibindo os sistemas enzimáticos para a formação da mesma (Haslam, 1995; Jorge et al., 1996, Akinpelu, 2001).

\section{CONCLUSÃ̃o}

O extrato hidroalcóolico do cajueiro (Anacardium occidentale Linn.) produziu significante atividade antimicrobiana in vitro sobre as linhagens de Staphylococcus aureus de origem humana hospitalar resistentes (MRSA) e sensíveis a meticilina (MSSA). Assim, podemos concluir que o cajueiro apresenta-se como uma eficaz alternativa terapêutica para infecções provocadas por Staphylococcus aureus, e de baixo custo e de fácil acesso a população, uma vez que já está difundido seu uso na medicina popular.

\section{REFERÊNCIAS}

Agra MF, França PF, Barbosa-Filho JM 2007. Synopsis of the plants known as medicinal and poisonous in Northeast of Brazil. Rev Bras Farmacogn 17: 114-140.

Akinpelu DA 2001 Antimicrobial activity of Anacardium occidentale bark. Fitoterapia 72: 286-287.

Antunes RMP, Lima EO, Pereira MSV, Camara CA, Arruda TA, Catão RMR, Barbosa TP, Nunes XP, Dias CS, Silva TMS 2006. Atividade antimicrobiana "in vitro" e determinação da concentração inibitória mínina (CIM) de fitoconstituintes e produtos sintéticos sobre bactérias e fungos leveduriformes. Rev Bras Farmacogn 16: 517-524.

Barbosa-Filho JM, Vasconcelos THC, Alencar AA, Batista LM, Oliveira RAG, Guedes DN, Falcão HS, Moura MD, Diniz MFFM, Modesto-Filho J 2005. Plants and their active constituents from South, Central, and 
North America with hypoglycemic activity. Rev Bras Farmacogn 15: 392-413.

Barbosa-Filho JM, Medeiros KCP, Diniz MFFM, Batista LM, Athayde-Filho PF, Silva MS, Cunha EVL, Almeida JRGS, Quintans-Júnior LJ 2006. Natural products inhibitors of the enzyme acetylcholinesterase. Rev Bras Farmacogn 16: 258-285.

Cebalhos BSO, Urtiga RF, Barbosa RCSBC, Lima EO 1993. Atividade Antimicrobiana de produtos naturais sobre Staphylococcus aureus e Pseudomonas aeruginosa isoladas de águas recreacionais. Rev Bras Farm 74: 4-6.

Cechinel Filho V, Yunes AR 1998. Estratégias para a obtenção de compostos farmacologicamente ativos a partir de plantas medicinais. Conceitos de modificação estrutural para otimização da atividade. Quim Nova 21: 99-105.

Couto RC, Pedrosa TMG 1999. Infecções hospitalares no Brasil e no Mundo. In: Couto, Renato Camargos, Pedrosa, TMG; Nogueira, JM. (org.) Infecção Hospitalar: Epidemiologia e Controle. 2. ed. Rio de Janeiro: Medsi, p. 3 - 4.

Cowan MM 1999. Plants products as antimicrobial agents. Clin Microbiol Rev 12: 564-582.

Duarte MCT, Figueira GM, Pereira B, Magalhães PM, Delarmelina C 2004. Atividade antimicrobina de extratos hidroalcoólicos de espécies da coleção de plantas medicinais CPQBA/UNICAMP. Rev Bras Farmacogn 14(Supl. 1): 6-8.

Falcão HS, Lima IO, Santos VL, Dantas HF, Diniz MFFM, Barbosa-Filho JM, Batista LM 2005. Review of the plants with anti-inflammatory activity studied in Brazil. Rev Bras Farmacogn 15: 381-391.

Freitas FIS 1992. Caracterização fenotípica de amostras hospitalares de Staphylococcus aureus isoladas no Estado da Paraíba. 56f. Dissertação de Mestrado, Universidade Federal da Paraíba.

Haslam E 1995. Natural polyfenols (vegetable tannins) as drugs: Possible modes of action. J Nat Prod 59: 205-215.

Jawetz E, Melnick J, Adelberg E 1968. Microbiologia médica. 5. ed. Rio de janeiro: Guanabara, p. 15-17

Jorge LIF, Silva GA, Ferro VO 1996. Diagnose laboratorial dos frutos de Anacardium occidentale L. (caju). Rev Bras Farmacogn 5: 55-69.

Kamtchouing P, Sokeng DS, Moundipa FP, Watcho P, Jatsa BH, Lontsi D 1998. Protective role of Anacardium occidentale extract against streptozotocin-induced in rats. J Ethnopharmacol 62: 95-99.

Kubo I, Kinst-Hori I, Yokokawa Y 1994. Tyrosinase inhibitors from Anacardium occidentale fruits. J Nat Prod 57: 545-551.

Laurens A, Giono Barber, P Sylla, David-Prince 1992. Etude de lфaction antibacterenne dфextraits dфAnacardium occidentale L. Annales Pharmaceutiques Françaises 40: 143-146.

Lima MRF, Ximenes CPA, Luna JS, Sant'Ana AEG 2006. The antibiotic activity of some Brazilian medicinal plants. Rev Bras Farmacogn 16: 300-306.

Melo AFM, Santos EJV, Souza LFC, Carvalho AAT, Pereira MSV, Higino JS 2006. Atividade antimicrobiana in vitro do extrato de Anacardium occidentale L. sobre espécies de Steptococcus. Rev Bras Farmacogn 16:
202-205.

Michelin DC, Moreschi PE, Lima AC, Nascimento GGF, Paganelli MO, Chaud MV 2005. Avaliação da atividade antimicrobiana de extratos vegetais. Rev Bras Farmacogn 15: 316-320.

Morais SM, Dantas JDP, Silva ARA, Magalhães EF 2005. Plantas medicinais usadas pelos índios Tapebas do Ceará. Rev Bras Farmacogn 15: 169-177.

Mota M 2004. Disponível em http://www.jangadabrasil.com. br. Acesso em: 27/julho/2004.

Nascimento GG, Locatelli J, Freitas PC 2000. Antibacterial activity of plants extracts and phytochemical on antibiotic-resistant bacteria. Braz J Microbiol 31: 247-256.

NCCLS 1988. National Comittee for Clinical Laboratory Standards. Methods for diluition antimicrobial susceptibility test for bacteria that grow aerobically. 2. ed. Tentative Standart. Document M7 - T2.

Novais TS, Costa JFO, David JPL, David JM, Queiroz LP, França F, Giulietti AM, Soares MBP, Santos RR 2003. Atividade antibacteriana em alguns extratos de vegetais do semi-árido brasileiro. Rev Bras Farmacogn 13(Supl. 2): 5-8.

Olajide OA, Aderogba MA, Adedapo AD, Makinde JM 2004. Effects of Anacardium occidentale stem bark extract on in vivo inflammatory models. $J$ Ethnopharmacol 95: 139-142.

Oliveira F, Salto ML 1987/1989. Alguns vegetais brasileiros empregados no tratamento de diabetes. Rev Bras Farmacogn 2/4: 170-196.

Oliveira FP, Lima EO, Siqueira Júnior JP, Souza EL, Santos BHC, Barreto HM 2006. Effectiveness of Lippia sidoides Cham. (Verbenaceae) essential oil in inhibiting the growth of Staphylococcus aureus strains isolated from clinical material. Rev Bras Farmacogn 16: 510-516.

Oliveira RAG, Lima EO, Souza EL, Vieira WL, Freire KRL, Trajano VN, Lima IO, Silva-Filho RN 2007. Interference of Plectranthus amboinicus (Lour.) Spreng essential oil on the anti-Candida activity of some clinically used antifungals. Rev Bras Farmacogn 17: 186-190.

Pessini GL, Holetz FB, Sanches NR, Cortez DAG, Dias-Filho BP, Nakamura CV 2003. Avaliação da atividade antibacteriana e antifúngica de extratos de plantas utilizados na medicina popular. Rev Bras Farmacogn 13(Supl. 1): 21-24.

Stratton CW 2000 Nuances in antimicrobial susceptibility testing for resistant gram-positive organisms. Antimicrobics and Infectious Diseases Newsletter 18: 57-64

Xu HX, Lee F 2001. Song activity of plant flavonoids against antibiotic- resistant bacteria. Phytother Res 15: 39-43. 